\title{
Kinetics and Mechanistic Oxidation of $\ell$-Leucine and $\ell$-Valine by 1,3-Dichloro-5,5-dimethylhydantoin in Aqueous Acetic Acid Medium
}

\author{
Shweta Neeraj ${ }^{1}$, S.S. Parihar ${ }^{1}$, A.P. Dwive di ${ }^{2}$ \\ ${ }^{1}$ Department of Chemistry, Govt. Girls P.G. College (NAAC) Rewa-486001 (M.P.) India 2Department of \\ chemistry, Govt. Sanjay Gandhi Smrati Auto., P.G., College Sidhi M.P India
}

*Corresponding Author: Shweta Neeraj, Department of Chemistry, Govt. Girls P.G. College (NAAC) Rewa-486001 (M.P.) India

\begin{abstract}
The kinetics of oxidation of laevo-Leucine and laevo-Valine essential amino acids [AA] have been investigated by 1,3-dichloro-5,5-dimethylhydantoin (DCDMH) in aqueous acetic acid medium in presence of mineral acid. The observed rate of oxidation is first-order with respect to [AA], and [DCDMH]. The rate of reaction is catalysed by $\left[\mathrm{H}^{+}\right]$ion. The rate ofoxidation increases with rise in percentage of solvent composition. The reaction fails to initiate polymerization with added monomer acrylonitrile and free radical mechanism is discorded. The stoichiometric ratio 1:1 of the reaction yields corresponding aldehyde as a main product of oxidation. The thermodynamic parameters have been evaluated and reaction constants involved in the probable mechanism was derived in consonance with the kinetic findings.
\end{abstract}

Keywords: Consonance, composition, oxidation, parameters, aldehyde.

\section{INTRODUCTION}

In the recent development, $\mathrm{N}$-halo compounds are the main source of positive halogen, have been employed as oxidant for a variety of substrates in different medium. ${ }^{[1,2]}$ One such $\mathrm{N}$-halo compound is 1,3-dichloro-5,5-dimethylhydantoin (DCDMH) finds application in organic synthesis ${ }^{[3]}$ and also due to kinetic aspects. ${ }^{[4]}$ DCDMH is used as an redox in analytical chemistry. It is widely used as a disinfectant and killing germs used in sterilization for industrial water, tap water, aquaculture due to presence of chlorine, $\mathrm{H}_{2} \mathrm{O}^{+} \mathrm{Cl}$ and $\mathrm{HOCl}$. This oxidant has found few applications as oxidizing agent for the catalysed and uncatalysed organic substrates ${ }^{[5-8]}$ reactions. The kinetics and oxidation of amino acids by $\mathrm{N}$-halo oxidants ${ }^{\left[{ }^{9-15]}\right.}$ have already been earlier acclaimed by several authors. It has been observed that the nature of reacting species and its way of participation in the reaction mechanism depends upon the nature of halogen atom and groups attached to the nitrogen in amino acids in addition to the reaction conditions. Amino acids namely $\ell$-leucine and $\ell$-valine are the main biologically important compounds obtained from the hydrolysis of proteins. According to available literature no wok on the kinetics of oxidation of above amino acids with 1,3-dichloro-5, 5-dimethylhydantoin in aqueous acetic acid medium in the presence of acid was reported. Hence we report here the result of above probe.

\section{EXPERIMENTAL}

All the chemicals and solvents employed were of standard grade. The fresh solutions of the required reagents were prepared in double distilled water and were standardized before the reactions were carried out. All the reactions were studied in the thermostat maintained at temperature $\pm 0.1^{0} \mathrm{C}$. The reaction was initiated by mixing previously thermostated solutions of the reactants at experimental temperature. The reaction was performed by maintaining large excess of $[\mathrm{AA}]$ over [DCDMH]. The reaction was followed by determining the unreacted oxidant iodometrically. The rate constants were evaluated from the slopes of linear plots of $\log$ (titre) vs. time. The values of rate constants for the oxidation reactions were reproducible within $\pm 3 \%$.

\section{RESULTS AND DISCUSSION}

Various factors influencing the rate of reaction occurring between $\ell$-amino acids and oxidizing agent 1,3-dichlolro-5,5-dimethylhydantoin such as concentration of oxidizing agent, substrates ( $\ell$-leucine, $\ell$ valine), $\mathrm{H}^{+}$ions, primary salts, 5-5-dimethylhydantoin (DMH) and percentage composition of acetic acid and temperature have been studied. The [DCDMH] was varied from $1.25 \times 10^{-3}$ to $5.00 \times 10^{-3}$ (mol $\mathrm{dm}^{-3}$ ) at constant concentration of other reagents at fixed temperature. The pseudo first-order rate 
constant was found to be constant. $K_{\mathrm{obs}}$ was evaluated from the slope of plots of log [DCDMH] Vs. time was found to be linear. The kinetic runs were carried out with various initial concentrations of $\ell$-leucine and $\ell$-valine varying from $1.00 \times 10^{-2}$ to $5.00 \times 10^{-2}\left(\mathrm{~mol} \mathrm{dm}^{-3}\right)$ at fixed concentration of oxidant, $\mathrm{H}^{+}$ ion, solvent composition and temperature. The rate constants $\left(\mathrm{k}_{\mathrm{obs}}\right)$ were found to increase with $[\ell-$ AA] (Table 1). The plots of $\mathrm{k}_{1}$ vs. [AA] and $\mathrm{k}_{1}^{-1}$ against $[\mathrm{AA}]^{-1}$ (Figs. 1,2), were found to be linear with unit slope for the two amino acids passing through origins $\left(\mathrm{R}^{2}>0.9892\right)$ indicating the first-order dependence on [AA]. The reaction rate constant with various $\left[\mathrm{H}^{+}\right] 0.25$ to $1.25\left(\mathrm{~mol} \mathrm{dm}^{-3}\right)$ was determined. The pseudo first-order rate constants were found to increase as the $\mathrm{H}^{+}$ion concentration increases keeping concentration of all other reagent constants (Table 2).

The primary salts effects have shown almost insignificant effect on rate of oxidation, whereas the addition of acrylonitrile monomer fails to induce any polymerization clearly indicating the absence of free radicals in the reaction mixture. Moreover the added 5,5-dimethylhydantoin (DMH) shows the retarding effect in rate of oxidation suggests that the pre-equilibrium step involves the hydrolysis of DCDMH yielding DMH and $\mathrm{HOCl}$ that undergo protonation give rise $\mathrm{H}_{2} \mathrm{O}^{+} \mathrm{Cl}$ reacting species of oxidant. The addition of varying concentration $\left[\mathrm{Cu}^{2+}\right]$ catalyst slightly shows the accelerating rate of oxidation under investigation. The stiochiometry was found to be 1 mole of DCDMH, per mole of each AA. The products according to the stiochiometry were corresponding aldehydes i.e. iso valeraldehyde and butyraldehyde, which were tested from the distillate with 2,4-dinitrophenylhydrazine (DNP) by forming their yellow DNP derivative. The products were also examined by other chemical tests. The effect of temperature was studied between 298 to $313 \mathrm{~K}$ by keeping all the concentrations of reagents constant. The values of activation parameters such as energy of activation (Ea) was found to be (39.93 and $\left.40.06 \mathrm{~kJ} \mathrm{~mol}^{-1}\right) ; \Delta \mathrm{H}^{\#}=\left(29.06\right.$ and $\left.29.47 \mathrm{~kJ} \mathrm{~mol}^{-1}\right), \Delta \mathrm{G}^{\#}=84.93$ to 85.47 and $\Delta \mathrm{S}^{\#}=-182.09$ to $\left.185.03 \mathrm{JK}^{-1} \mathrm{~mol}^{-1}\right)$.

\section{Mechanism}

On the basis of kinetic results and considering the protonated remote profile reacting species $\mathrm{H}_{2} \mathrm{O}^{+} \mathrm{Cl}$, the mechanism can be represented by the scheme as :
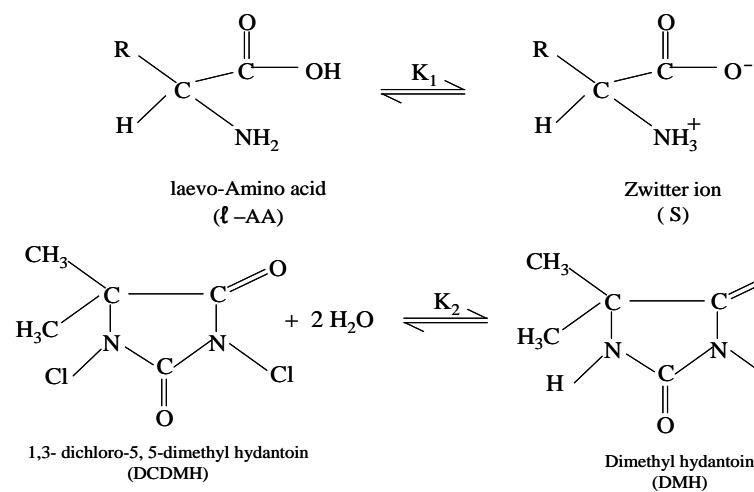

$$
\text { Zwitter ion }
$$



$$
\mathrm{HOCl}+\mathrm{H}^{+} \stackrel{\mathrm{K}_{3}}{\rightleftharpoons} \underset{\begin{array}{c}
\mathrm{H}_{2} \mathrm{OCl}^{+} \\
\text {(Protonated) }
\end{array}}{{ }^{+}}
$$

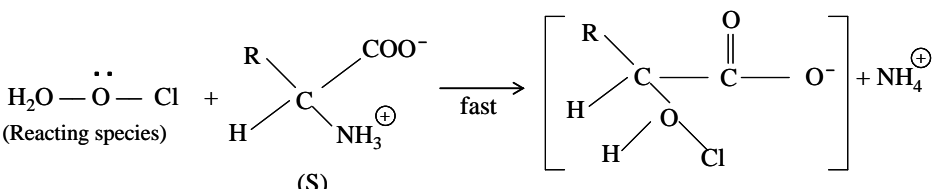

(S)

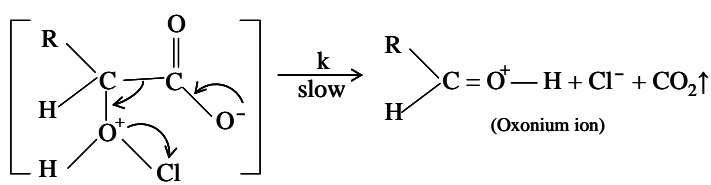

$$
\begin{aligned}
\mathrm{R}>\mathrm{C}=\mathrm{O}_{\mathrm{H}}^{+} \stackrel{\mathrm{OHH}_{2}}{\mathrm{NH}_{4}^{+}+\mathrm{Cl}^{-}} \underset{\text { fast }}{\stackrel{\mathrm{fast}}{\longrightarrow}} \begin{array}{l}
\mathrm{R} \\
\mathrm{H}
\end{array} \mathrm{NH}_{4} \mathrm{Cl}=\mathrm{O}+\mathrm{H}_{3} \mathrm{O}^{+}
\end{aligned}
$$


where, $\mathrm{R}=-\mathrm{CH}_{2}-\mathrm{CH}-\left(\mathrm{CH}_{3}\right)$ and $-\mathrm{CH}-\left(\mathrm{CH}_{3}\right)$ for corresponding aldehydes.

The rate law according to scheme can be derived as:

$$
\begin{aligned}
\text { Rate } & =\mathrm{k} \text { [complex }] \\
\text { Rate } & =\frac{\mathrm{k} \mathrm{k}_{1} \mathrm{k}_{2} \mathrm{k}_{3}\left[\mathrm{H}^{+}\right][\mathrm{DCDMH}][\mathrm{S}]}{[\mathrm{DMH}]} \\
\mathrm{k}_{\mathrm{obs}} & =\frac{\text { Rate }}{[\mathrm{DCDMH}]_{\mathrm{T}}}=\frac{\mathrm{k} \mathrm{k}_{1} \mathrm{k}_{2} \mathrm{k}_{3}[\mathrm{~S}]\left[\mathrm{H}^{+}\right]}{[\mathrm{DMH}]+\mathrm{K}_{2}}
\end{aligned}
$$

The reciprocal of $\mathrm{k}_{\mathrm{obs}}$ as $\mathrm{k}^{-1}$

$$
=\frac{1}{\mathrm{k} \mathrm{k}_{1} \mathrm{k}_{3}[\mathrm{~S}]}\left\{\frac{[\mathrm{DMH}]}{\mathrm{k}_{2}\left[\mathrm{H}^{+}\right]}+1\right\}
$$

Equation (8) explains all the experimental facts.

The observed order of reactivity is found as:

$\ell$-leucine $\left(\mathrm{CH}_{3}\right)_{2}-\mathrm{CH}-\mathrm{CH}_{2} \mathrm{CH} \mathrm{NH} \mathrm{H}_{2} \mathrm{COOH}>\ell$-valine $\left(\mathrm{CH}_{3}\right)_{2}-\mathrm{CH}-\mathrm{CH}-\mathrm{NH}_{2} \mathrm{COOH}$

The electron deficient species is formed at the transition state, stabilized by inductive effect which causes the fission of bond expelling protons. The complex is short lived, breaks down in the rate determining step to give the final products (iso valeraldehyde and butyraldehyde). Considering deamination, effect of electrophile $\mathrm{H}_{2} \mathrm{O}^{+} \mathrm{Cl}$ and domaincy of inductive effect support the above order of mechanism. The rate of reaction depends on the total electron density on carbon atom. The value of energy of activation is measure of above order of reactivity. Both the $\ell$-AA studied possesses the identical operative mechanism. The values of free energy and entropy of activation are important in monitoring the rates of reactions through the enthalpy factor appear to be more predominating hence reaction is enthalpy controlled.

\section{CONCLUSiON}

Electrophilic $\mathrm{H}_{2} \mathrm{O}^{+} \mathrm{Cl}$ attack of the species on the carboxylate an ion of amino acid leads to the formation of short lived an intermediate complex at transition state which then decomposes in a slow step. The loss of entropy was noticed in the present study. The nature of the transition state is the same for two amino acid probed by the order of observed enthalpy of activation. The thermodynamic data obtained supported the proposed mechanism.

Table1. Dependence of rate on varying concentration of Amino Acid

$\left.10^{3} \times[\mathrm{DCDMH}](\mathrm{mol} \mathrm{dm})^{-3}\right)=2.50(1,2) ;$

$\left[\mathrm{H}^{+}\right]\left(\mathrm{mol} \mathrm{dm}^{-3}\right)=0.80(1,2)$;

$\mathrm{CH}_{3} \mathrm{COOH} \cdot \mathrm{H}_{2} \mathrm{O}, \%(\mathrm{v} / \mathrm{v})=50(1,2) ;$

Temp. $\mathrm{K}=303(1,2)$

\begin{tabular}{|c|c|c|c|}
\hline S. No. & $\begin{array}{c}10^{2} \times[\ell-A m i n o ~ a c i d] \\
\left(\mathrm{mol} \mathrm{dm}^{-3}\right)\end{array}$ & \multicolumn{2}{|c|}{$\mathrm{k}_{1} \times 10^{4}(\mathrm{~s} \stackrel{-1}{\longrightarrow}$} \\
\cline { 3 - 4 } & & $\begin{array}{c}\ell-\text { Leucine } \\
\left(\mathrm{CH}_{3}\right)_{2}-\mathrm{CH}-\mathrm{CH}_{2} \mathrm{CH} \mathrm{NH}_{2} \mathrm{COOH}(1)\end{array}$ & $\begin{array}{c}\ell \text {-Valine } \\
\left(\mathrm{CH}_{3}\right)_{2}-\mathrm{CH}-\mathrm{CH}-\mathrm{NH}_{2} \mathrm{COOH}(2)\end{array}$ \\
\hline 1. & 1.00 & 1.94 & 1.31 \\
\hline 2. & 1.25 & 2.87 & 1.74 \\
\hline 3. & 2.00 & 3.43 & 2.75 \\
\hline 4. & 2.50 & 4.05 & 3.82 \\
\hline 5. & 3.33 & 5.25 & 4.52 \\
\hline 6. & 4.00 & 6.41 & 5.33 \\
\hline 7. & 5.00 & - & 6.90 \\
\hline
\end{tabular}


Kinetics and Mechanistic Oxidation of $\ell$-Leucine and $\ell$-Valine by 1,3-Dichloro-5,5-dimethylhydantoin in Aqueous Acetic Acid Medium

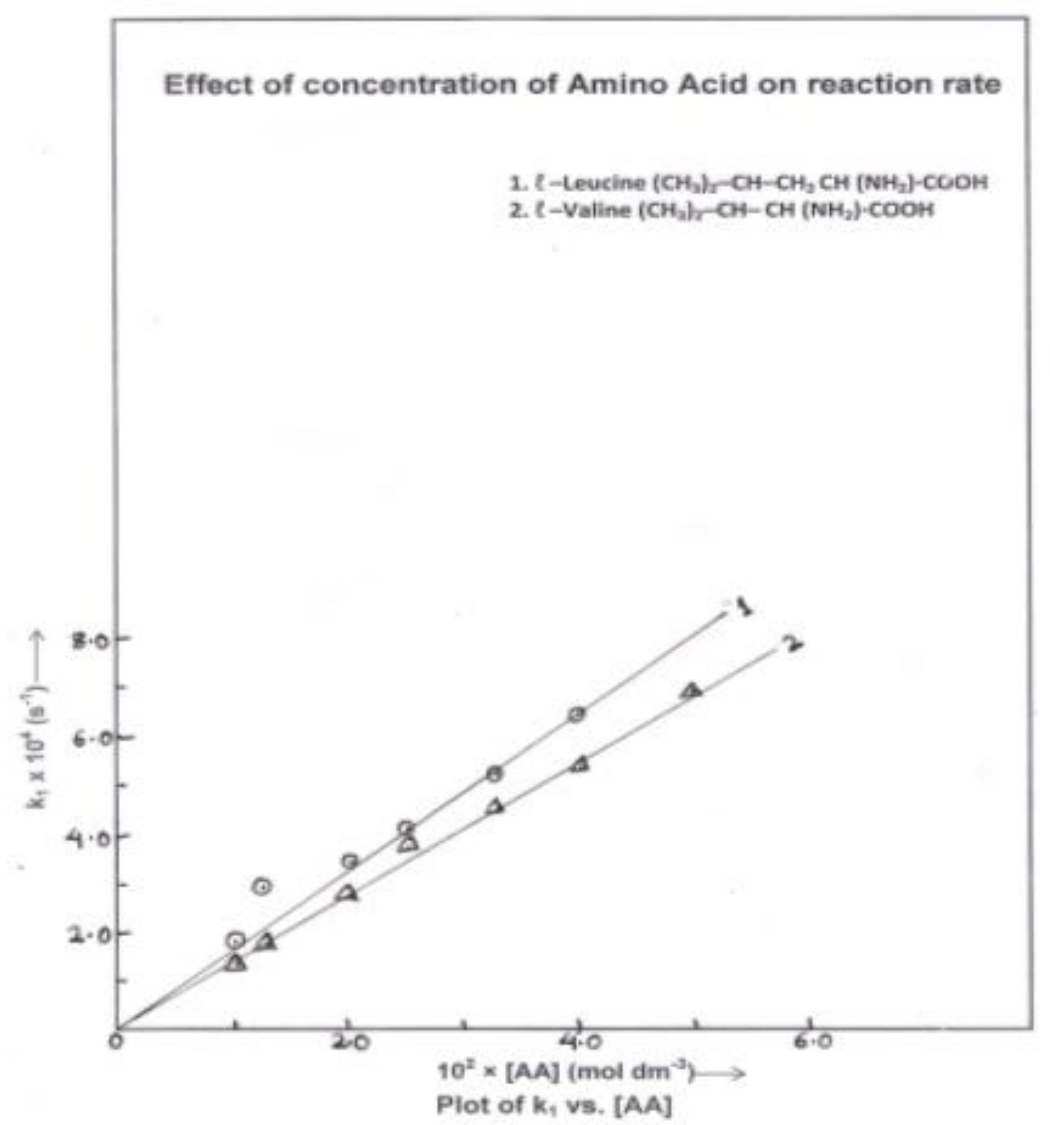

Fig1. $10^{3}[\mathrm{DCDMH}]\left(\mathrm{mol} \mathrm{dm^{-3 }}\right)=2.50(1,2) ;\left[\mathrm{H}^{+}\right]\left(\right.$mold $\left.\mathrm{m}^{-3}\right)=0.80(1,2) ; \mathrm{CH}_{3} \mathrm{COOH}-\mathrm{H}_{2} \mathrm{O} \%,(v / v)=50(1,2)$; Temp. $K=303(1,2)$

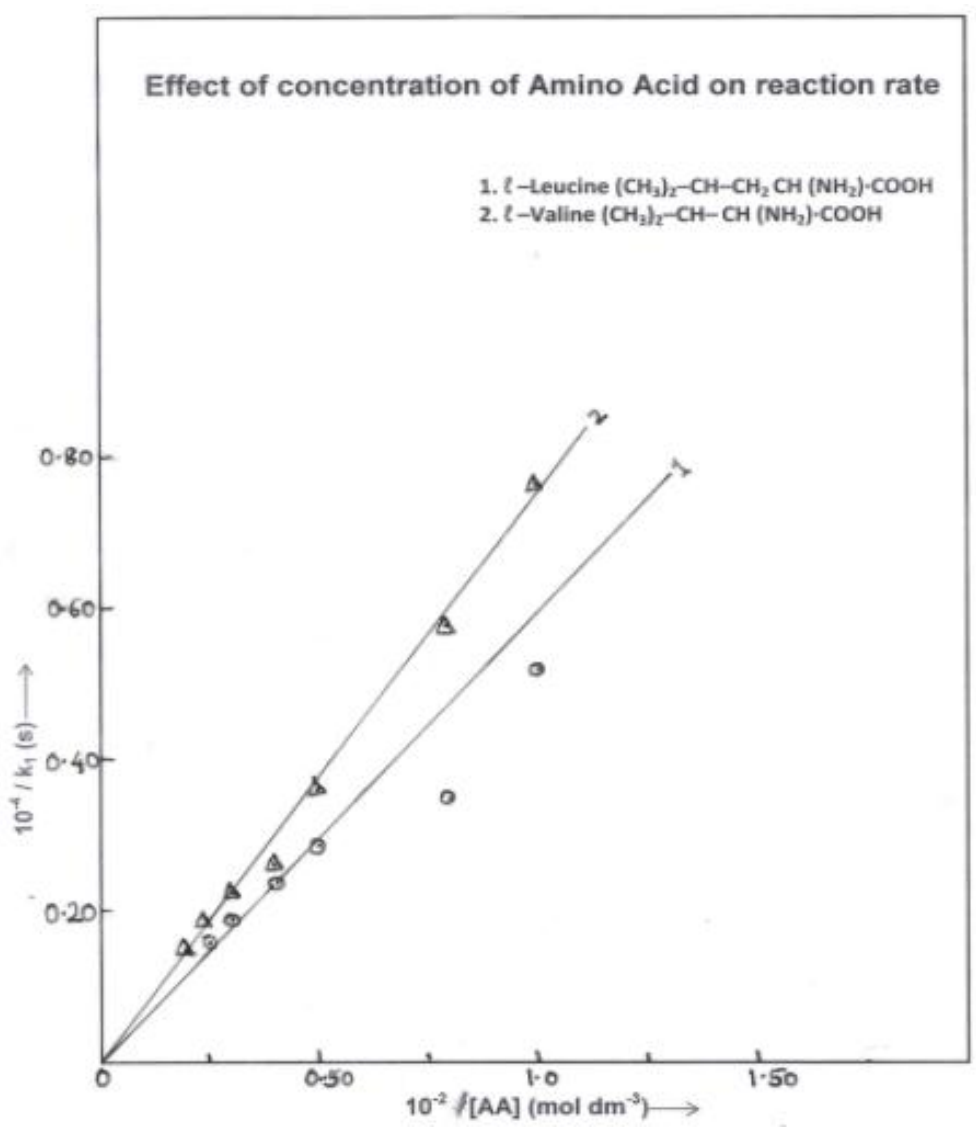

Fig2. Double reciprocal plot of $1 / \mathrm{k} v \mathrm{~s} .[A A]^{-1} 10^{3 *}[\mathrm{DCDMH}]\left(\mathrm{mol} \mathrm{dm}^{-3}\right)=2.50(1,2) ;\left[\mathrm{H}^{+}\right]\left(\mathrm{mol} \mathrm{dm}^{-3}\right)=0.80(1,2)$; $\mathrm{CH}_{3} \mathrm{COOH}-\mathrm{H}_{2} \mathrm{O} \%,(v / v)=50(1,2)$; Temp. $\mathrm{K}=303(1,2)$ 
Kinetics and Mechanistic Oxidation of $\ell$-Leucine and $\ell$-Valine by 1,3-Dichloro-5,5-dimethylhydantoin in Aqueous Acetic Acid Medium

Table2. Dependence of rate on concentration of Acid

$10^{3} \times[\mathrm{DCDMH}]\left(\mathrm{mol} \mathrm{dm}{ }^{-3}\right)=2.50(1,2) ;$

$10^{2} \times[\mathrm{AA}]\left(\mathrm{mol} \mathrm{dm}^{-3}\right)=2.50(1,2) ;$

$\mathrm{CH}_{3} \mathrm{COOH} \cdot \mathrm{H}_{2} \mathrm{O}, \%(\mathrm{v} / \mathrm{v})=50(1,2)$;

Temp. $\mathrm{K}=303(1,2)$

\begin{tabular}{|c|c|c|c|}
\hline \multirow[t]{2}{*}{ S. No. } & \multirow{2}{*}{$\begin{array}{c}{\left[\mathrm{H}^{+}\right]} \\
\left(\mathrm{mol} \mathrm{dm} \mathrm{dm}^{-3}\right)\end{array}$} & \multicolumn{2}{|c|}{$\mathrm{k}_{1} \times 10^{4}\left(s^{-1}\right) \rightarrow$} \\
\hline & & $\begin{array}{c}\ell \text {-Leucine } \\
\left(\mathrm{CH}_{3}\right)_{2}-\mathrm{CH}-\mathrm{CH}_{2} \mathrm{CH} \mathrm{NH} \mathrm{NH}_{2} \mathrm{COOH}(1)\end{array}$ & $\begin{array}{c}\ell \text {-Valine } \\
\left(\mathrm{CH}_{3}\right)_{2}-\mathrm{CH}-\mathrm{CH}-\mathrm{NH}_{2} \mathrm{COOH}(2)\end{array}$ \\
\hline 1. & 0.25 & 1.19 & 0.91 \\
\hline 2. & 0.33 & 1.61 & 1.34 \\
\hline 3. & 0.40 & 2.25 & 1.67 \\
\hline 4. & 0.50 & 2.52 & 2.13 \\
\hline 5. & 0.80 & 4.05 & 3.82 \\
\hline 6. & 1.00 & 5.11 & 4.19 \\
\hline 7. & 1.25 & 6.31 & 4.96 \\
\hline
\end{tabular}

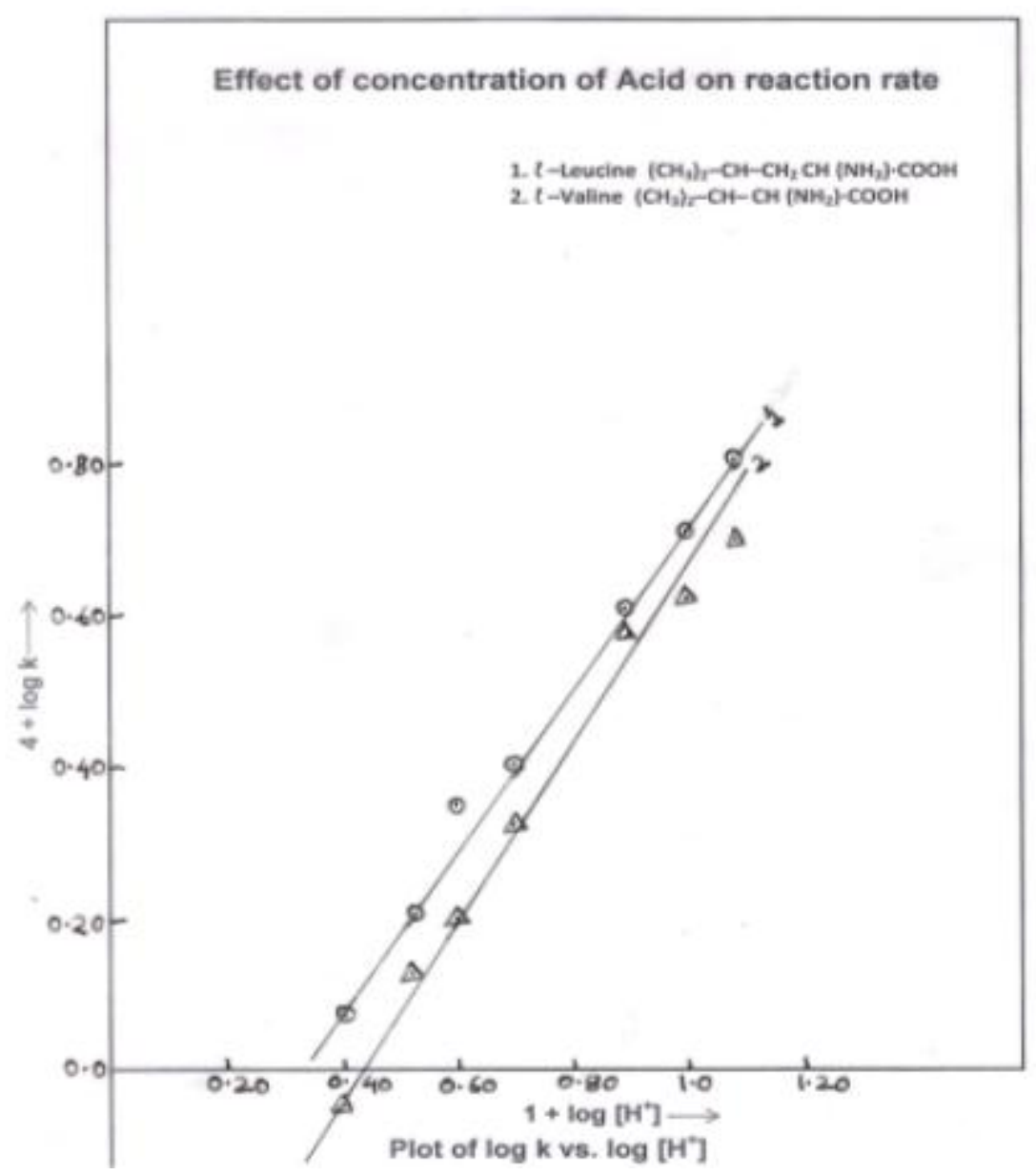

Fig3. $10^{3 *}[D C D M H]\left(m o l ~ d m^{-3}\right)=2.50(1,2) ; 10^{2 *}[A A]\left(\mathrm{mol} \mathrm{dm}^{-3}\right)=2.50(1,2) ; \mathrm{CH}_{3} \mathrm{COOH}^{2} \mathrm{H}_{2} \mathrm{O} \%,(\mathrm{v} / \mathrm{v})=50$ (1,2); Temp. $K=303(1,2)$

\section{REFERENCES}

[1] Mohamed Farook, N.A., Seyed Dameem, Mungesan, A., and Kanagaraj, M. ; E. Journal Chem., 2004, 132136

[2] Balasubramaniyan, P.V., and Mathiyalagan, N.; J. Chem. Pharm. Res., 2011, 3, 522.

[3] Thenraja, D., Subramanian, P., and Srinivasen, C.; J. Chem. Soc., Perkin Trans., 2002, 2, 2125.

[4] Kolvari, E., Ghorbani-Choghamaranani, A., Salehi, P., Shirini, F., and Zolfigol, M.A.; J. Iran. Chem. Soc., 2007, 4, 126. 
Kinetics and Mechanistic Oxidation of $\ell$-Leucine and $\ell$-Valine by 1,3-Dichloro-5,5-dimethylhydantoin in Aqueous Acetic Acid Medium

[5] Mukaiyama, T., Mastsuo, J.I., Lida, D., and Kitagawa, H.; Chem. Lett. 2001, 8, 846.

[6] Singh, A.K., Singh, V., Rahmani, S., and Singh, B.; J. Mol. Catal. A, 2003, 91, 197.

[7] Vivekanandan, K., and Nambi, K.; Tetrahydran Lett., 1970, 11, 2039.

[8] Kutti Rani, S., Eswaramurthy, D., Bilal, Mohamed, T., and Palanichaong, M.; Appl., Catal. A: General, 2009, 1-7, 369, (102).

[9] Katre, Y.R., Solanki, S.K.M., Sangeeta, P, and Joshi, G.K.: Asian J. Chem., 2005, 17, 423.

[10] Mahadevappa, D.S., Puttaswamy, and Made Gowda, N.M. ; Proc. Indian Acad. Sci. (Chem. Sci.) 1988, 100(4), 261

[11] Puttaswamy, and Vaz, N.; J. Indian Chem. Soc., 2004, 479, 81

[12] Bisnoi, M.L., and Benerji, K.K.; J. Indian Chem. Soc., 1985, 41(24), 6049-6050.

[13] Vivekanandan, K., and Nambi, K.; J. Indian Chem. Soc., 1999, 76, 198-201.

[14] Malharrao, R., Thombare, and Gavisiddappa, S. Gokavi; J. Braz. Chem. Soc., 2014, 25, 1545-1551.

[15] Anil Kumar, J., Satpathy, K.K. and Nayak, P.L.; J. Chem. Soc. PerkinII, 1974, 328.

Citation: S. Neeraj et al., "Kinetics and Mechanistic Oxidation of $\ell$-Leucine and $\ell$-Valine by 1,3-Dichloro5,5-dimethylhydantoin in Aqueous Acetic Acid Medium", International Journal of Advanced Research in Chemical Science (IJARCS), vol. 5, no. 3, pp. 22-27, 2018. http://dx.doi.org/10.20431/2349-0403.0503005

Copyright: (C) 2018 Authors. This is an open-access article distributed under the terms of the Creative Commons Attribution License, which permits unrestricted use, distribution, and reproduction in any medium, provided the original author and source are credited. 